\title{
Systems Analysis and Engineering of the X-1 Advanced Radiation Source ${ }^{*}$
}

\author{
Gary E. Rochau, Jerome A. Hands, Paul S. Raglin, and Juan J. Ramirez
}

\author{
Sandia National Laboratories \\ P.O. Box 5800, MS-1178 \\ Albuquerque, NM 87185-1178
}

(505) $845-7543$

\section{ABSTRACT}

The X-1 Advanced Radiation Source, which will produce $\sim 16 \mathrm{MJ}$ in $\mathrm{X}$-rays, represents the next step in providing U.S. Department of Energy's Stockpile Stewardship Program with the high-energy, large volume, laboratory $\mathrm{x}$-ray sources needed for the Radiation Effects Science and Simulation (RES), Inertial Confinement Fusion (ICF), and Weapon Physics (WP) Programs. Advances in fast pulsed power technology and in z-pinch hohlraums on Sandia National Laboratories' Z Accelerator in 1997 provide sufficient basis for pursuing the development of $\mathrm{X}-1$. The plan for $\mathrm{X}-1$ follows a strategy based on scaling the $2 \mathrm{MJ}$ $x$-ray output achieved on $Z$ via an increment of 3 in $z$-pinch load current. The large volume $\left(>5 \mathrm{~cm}^{3}\right)$, high temperature $(>150$ $\mathrm{eV})$, temporally long ( $>10 \mathrm{~ns}$ ) hohlraums are unique outside of underground nuclear testing. Analytical scaling arguments and hydrodynamic simulations indicate that these hohlraums at temperatures of 230-300 $\mathrm{eV}$ will ignite the thermonuclear fuel and drive the reaction to a high radiation yield of 200 to $1000 \mathrm{MJ}$ in the laboratory. The Stockpile Stewardship Program relies on advanced experimental and modeling capabilities to certify the performance, survivability, and reliability of weapon components and subsystems in the absence of underground testing. X-1 will provide the high-fidelity experimental capability to certify the survivability of non-nuclear weapon components in hostile radiation environments. Non-ignition sources will provide cold $\mathrm{x}$-ray environments $(<15 \mathrm{keV})$ and high yield fusion burn sources will provide high fidelity worm $\mathrm{x}$-ray environments ( $15 \mathrm{keV}-80 \mathrm{keV})$. Material response in these regimes can not be simulated in the absence of underground nuclear testing and X-1 will provide a necessary and unique capability for RES.

The configuration of the X-1 Facility will depend on the specific applications experiment. The final power transmission system could vary from a simple vacuum insulator stack to a highly shielded vacuum chamber for containing the radiation and radioactive debris. The most challenging elements of facility design are driven by the high-yield ICF and RES experiments. The optimum configurations are being determined by a systems analysis approach. To accomplish this, the facility is characterized in terms of primary, secondary and support systems. Using a database approach, system definition and

\footnotetext{
"Sandia is a multiprogram laboratory operated by Sandia Corporation, a Lockheed Martin Company, for the United States Department of Energy under Contract DE-AC04-94AL85000
} 


\section{DISCLAMER}

This report was prepared as an account of work sponsored by an agency of the United States Government. Neither the United States Government nor any agency thereof, nor any of their employees, makes any warranty, express or implied, or assumes any legal liability or responsibility for the accuracy, completeness, or usefulness of any information, apparatus, product, or process disclosed, or represents that its use would not infringe privately owned rights. Reference herein to any specific commercial product, process, or service by trade name, trademark, manufacturer, or otherwise does not necessarily constitute or imply its endorsement, recommendation, or favoring by the United States Government or any agency thereof. The views and opinions of authors expressed herein do not necessarily state or reflect those of the United States Government or any agency thereof. 


\section{DISCLAIMER}

Portions of this document may be illegible in electronic image products. Images are produced from the best available original document. 
specifications are linked in such a fashion that as physics issues are addressed, the impact on facility design can be assessed. System tradeoffs can then be made and strategies for effective implementation can be developed.

Advanced driver and source technologies are being developed to ensure the success of constructing X-1. Experimental goals for these technologies are being identified and the risk assessments made to determine the best technology. An approach is being developed to select technologies that retain accelerator design flexibility, and emphasize proven technologies. A comprehensive risk identification, assessment and management program will be employed in conjunction with critical program reviews.

This paper will introduce the X-1 Advanced Radiation Source Facility Project, describe the systems analysis and engineering approach being used, and identify critical technology areas being researched.

\section{INTRODUCTION}

The X-1 Advanced Radiation Source, which will produce $\sim 16 \mathrm{MJ}$ in $\mathrm{X}$ rays, represents the next step in providing DOE's Stockpile Stewardship Program with the high-energy, large volume, laboratory $\mathrm{x}$ ray sources needed for the Radiation Effects Science and Simulation, Inertial Confinement Fusion (ICF), and Weapon Physics Programs. The mission of X-1 is to assist the United States Department of Energy in meeting the needs of its Strategic and Stockpile Stewardship plans. X-1's mission support DOE's mission to "be a responsible steward of the Nation's nuclear weapons" and to provide "continued United
States leadership in science and technology." The Stockpile Stewardship Program relies on the experimental and modeling capabilities necessary to certify the performance, survivability, and reliability of weapon components and subsystems in the absence of underground testing. X-1 will enhance the experimental capability necessary to certify weapon components in the absence of underground testing in the cold $\mathrm{x}$-ray regime $(<15 \mathrm{keV})$, and provide sufficient capability in the $15 \mathrm{keV}$ to $80 \mathrm{keV}$ range.

The goals of the X-1 Project cover three major phases. The first phase is the construction of an advanced facility capable of achieving high yield ( $\geq 200 \mathrm{MJ}$ ) fusion burn using fast $z$-pinch pulsed power technology. In the second phase, X-1 will demonstrate the capability of generating 16 MJ of x-ray energy, 1000 TW of X-ray power, and achieve hohlraum temperatures of $300 \mathrm{eV}$ in non-ignition experiments. The third phase will demonstrate the capability of driving a cryogenic capsule to fusion burn and high-energy yield to a minimum energy of $200 \mathrm{MJ}$.

$\mathrm{X}-1$ will utilize the integrated experience of the national ICF program in order to achieve its goals. The target physics experience derived from the laser, ion beam, and z-pinch programs will be utilized to design experiments and demonstrate ICF principles. Technology advances driven by the Nova Technical Contract, the National Ignition Facility, and the Sandia $Z$ Accelerator are essential to the success of the X-1 project. Experiments in these and other facilities are needed to provide the basic understanding and experience needed to support the X-1 design. 


\section{NEW RESULTS}

Advances in fast pulsed power technology and in z-pinch hohlraums on Sandia National Laboratories' Z Accelerator in 1997 and 1998 provide sufficient basis for pursuing the development of $X-1$. The $Z$ Accelerator has achieved a $X$-ray power of 290 TW and x-ray energy of nearly $2 \mathrm{MJ}$.

The plan for X-1 follows a strategy based on scaling the $2 \mathrm{MJ} \mathrm{X}$-ray output achieved on $\mathrm{Z}$ via an increment of 3 in z-pinch load current. The large volume $\left(>5 \mathrm{~cm}^{3}\right)$, high temperature $(>150 \mathrm{eV})$, temporally long ( $>10 \mathrm{~ns}$ ) hohlraums on the Z Accelerator are unique outside of underground nuclear testing. Analytical scaling arguments and hydrodynamic simulations indicate that these hohlraums at temperatures of $300 \mathrm{eV}$ will ignite thermonuclear fuel and drive the reaction to a high radiation yield of 200 to $1000 \mathrm{MJ}$ in the laboratory.

\section{SYSTEMS APPROACH}

The configuration of the X-1 Facility will depend on the specific applications experiment. The final power transmission system could vary from a simple vacuum insulator stack to a highly shielded vacuum chamber for containing the radiation and radioactive debris. The most challenging elements of facility design are driven by the high-yield ICF and RES experiments. The optimum configurations are being determined by a systems analysis approach. To accomplish this, the facility is characterized in terms of primary, secondary and support systems in an hierarchical relationship as shown in Figure 1. Using a database approach, system definition and specifications are linked in such a fashion that as physics issues are addressed, the impact on facility design can be assessed. System tradeoffs can then be made and strategies for effective implementation developed.

The focus of the systems approach is the Integrated Experiment (IE). The IE is the integrated package of radiation source application, target, z-pinch, experiment chamber, and diagnostics. All requirements and specifications are linked to the IE. As shown in Figure 2, various experiments with a wide range of requirements are expected to be performed on X-1. The tracking of these requirements is essential to the management of the project as well as the eventual management of the facility.

With a definition of the Integrated Experiment in place, primary, secondary, and support systems can be defined to support the experiment. As shown in Figure 3, a simple flow chart can show the hierarchical relationship of the systems. Between each system is an arrow which conveys requirements between the systems, the direction of the arrow determines which system defines the requirements and which system must meet the requirements. Thus, the arrows define the interface between systems. The systems analysis defines and evaluates options to meet the requirements.

To assist in the definition of the system options, a risk management approach is being utilized. Risk will be treated as a measurable quantity and managed throughout the project. A risk assessment study is being performed to identify and quantify the risk issues and to drive the research and development effort needed to manage and minimize risk throughout the project. 


\section{PRECONCEPTUAL DESIGN}

Essential to the Systems Analysis approach is a definition, even if preliminary, of major system components. This definition allows an analysis of the role of system components in the project planning. This definition must begin with the Integrated Experiment and end with waste disposal.

Several designs are being developed for the hohlraum and capsule, which we call the Target, three of which are shown in Figure 4. Each of these Target designs have a significant impact on the design and eventual utilization and cost of the X-1 Facility. The Dynamic Hohlraum, 4(c), is the most compact and requires the smallest facility, but has the highest technical risk for target performance. The Z-Pinch Driven Hohlraum, 4(a), is the largest, but may represent the lowest technical risk for the target while substantially increasing the construction risk for the pulsed power drive and the Experiment Chamber. The StaticWalled Hohlraum design, 4(b) represents a combination of both systems utilizing two dynamic hohlraums to drive the target capsule resulting in a risk level in-between the two other concepts.

Advanced pulsed power driver and $\mathrm{x}$-ray source technologies, referred to as Drivers, are being developed to ensure the success of constructing X-1. Experimental goals for these technologies are being identified and the risk assessments made to determine the best technology. The systems approach is being developed to select technologies that retain accelerator design flexibility, emphasize proven technologies, and conduct a comprehensive risk identification, assessment, and management program in conjunction with critical program reviews.

Two pulsed power designs are being examined at this time. One approach, shown in Figure 5, utilizes a technology similar to the $Z$ Accelerator. ${ }^{2}$ The second design, shown in Figure 6, utilizes a technology developed for the Hermes III Accelerator. ${ }^{3}$ The differentiating principle between the two designs is the location of the fluid/vacuum interface. In the Z-style, the interface is located close to the $\mathrm{x}$-ray source while in the Hermes III design the interface is located on the outer periphery of the accelerator. Both designs have advantages and will be closely analyzed during the Conceptual Design Phase of the X-1 Project.

Critical to all design concepts is the Experiment Chamber. This chamber must contain all the radioactive debris generated by the High Yield fusion reaction. ${ }^{4}$ An Experiment Chamber concept is shown in Figure 7. The design employs a "defense in depth" strategy. Multiple layers of protection are used to confine the radiation, shrapnel, debris, and vapor generated by the energy contained in the chamber. Integral to the aluminum chamber is a water shield tank to absorb the fusion neutrons and minimize the radiation dose outside the Experiment Chamber area of the facility.

The three major system areas: Targets, Drivers, and Experiment Chamber will require critical technology development for X-1 to be successful. Targets must be designed which can be constructed and the proper cryogenic conditions achieved in the Driver system. The Drivers must also be configured in a manner that the resulting fusion radiation source may be utilized by Integrated Experiments. The Experiment Chamber must be capable of containing all 
the radioactive products as well as being capable of being easily replaced to allow continued use of the facility. These and other technology development programs will be put in place during Conceptual Design to support the design, construction, and operation of X-1.

\section{PLAN}

The anticipated schedule for X-1 begins with an approval of Mission Need. Sandia is requesting approval in August 1998. Once approval of the mission is secured, Conceptual Design is expected to begin in early FY99 and, depending on necessary funding, finish with a Conceptual Design Report in FY00. Construction of the facility would begin in FYO2 and initial operation of the facility would occur in FY07 with all capabilities in place for High Yield operation. High Yield experiments are expected to begin in FY09.

\section{SUMMARY}

The X-1 Advanced Radiation Source is expected to be a facility for performing experiments that can utilize 200 to $1000 \mathrm{MJ}$ of radiation from a fusion source. It will also be used for experiments in a non- ignition mode. The facility will utilize fast pulsed power technology to drive $z$-pinch $\mathrm{x}$ ray sources to heat a cryogenic capsule and drive it to ignition and high yield burn. A systems analysis approach is being employed in the preconceptual design of the facility to identify critical systems and provide for an adequate risk management plan. The X-1 project expects to obtain a Justification of Mission need in August 1998 with high yield experiments beginning as early as 2009 .

\section{REFERENCES}

1. R. B. Spielman, et al., "Tungsten WireArray Z-Pinch Energetics at $200 \mathrm{TW}$ and 2 MJ," Phys. Plasmas, 5, no. 5, May 1998.

2. R.B. Spielman, et al., "PBFA II-Z: A 20-MA Driver for Z-Pinch Experiments," Proc. 10 $0^{\text {th }}$ IEEE Pulsed Power Conference, Vol. 1, Albuquerque, NM 1995, pp 396.

3. J.J. Ramirez, K.R. Prestwich, and I.D. Smith, "High-Power, Short-Pulse Generators Based on Induction Voltage Adders," Proceeding of the IEEE, Vol. 80, no. 6, June, 1992.

4. R. R. Peterson, et al., "Preconceptual Design of the X-1 Target Chamber," to be submitted to Fusion Technology. 


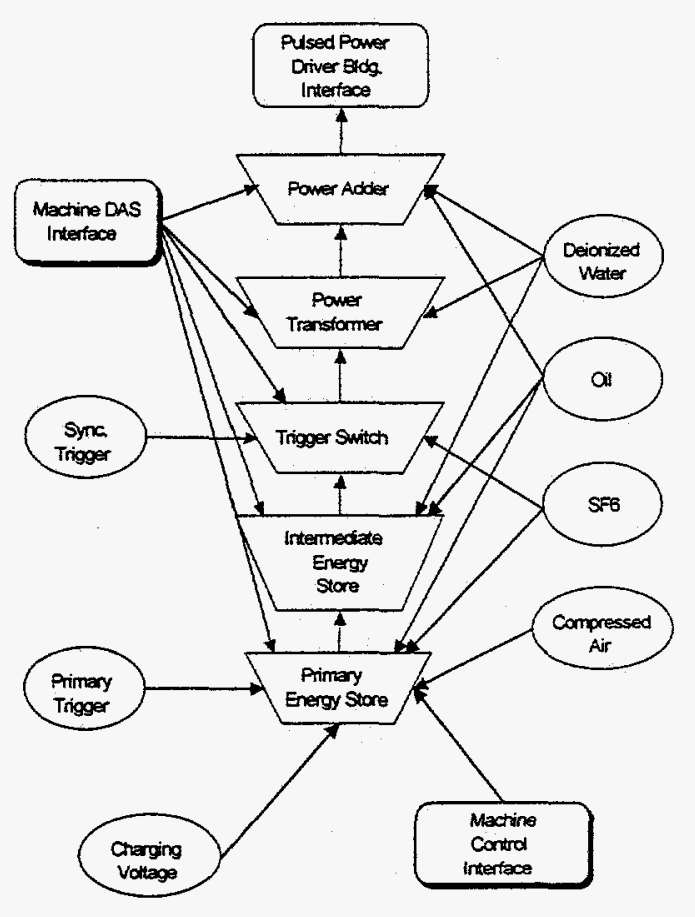

Figure 1. An example of the hierarchical relationship of major systems.

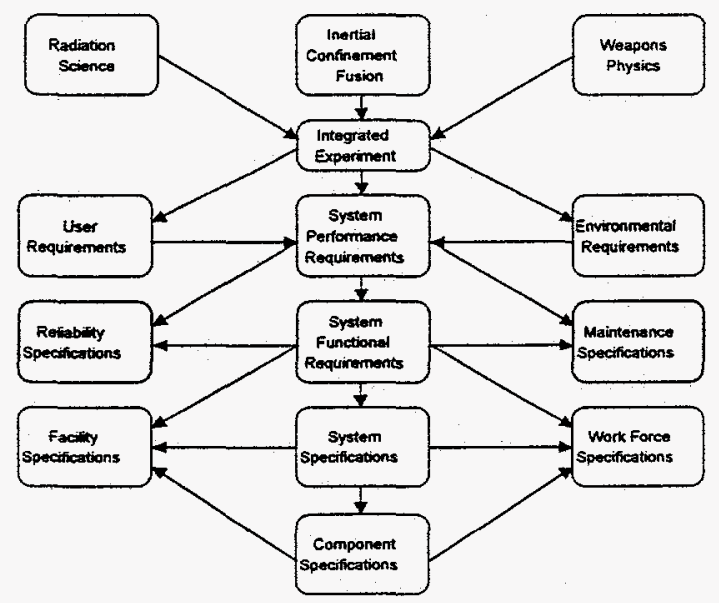

Figure 2. Systems Analysis Flow Chart showing the focus on the Experiments from which all systems specifications are derived.

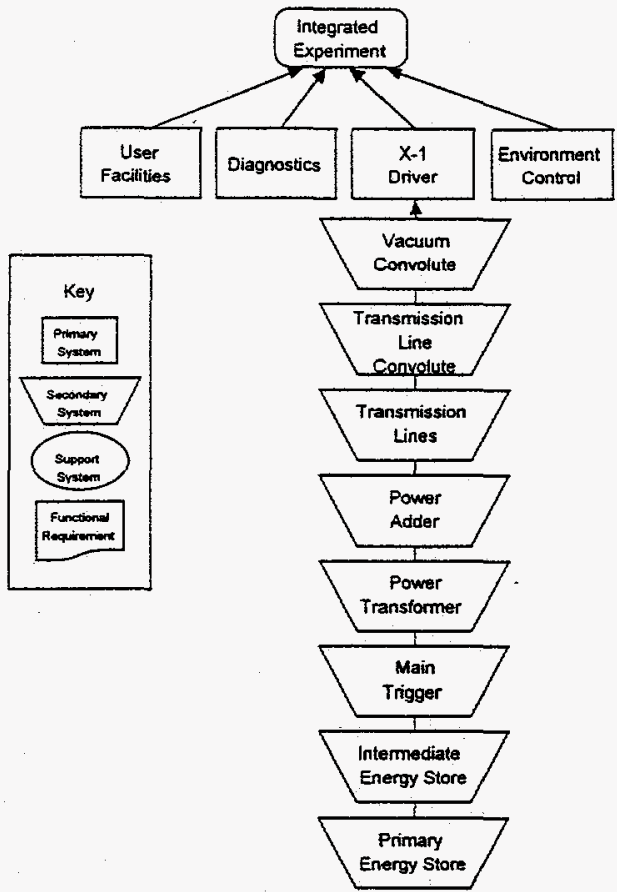

Figure 3. An example of a Systems Definition Chart showing major systems and interfaces. (a)

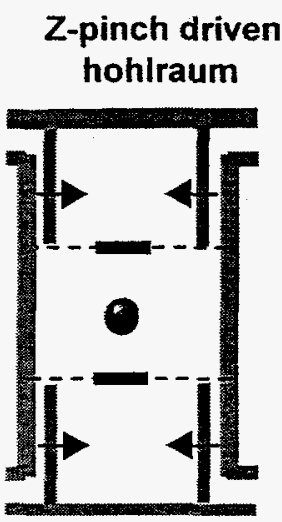

(b)

(c)

\section{Static-walled hohiraum}

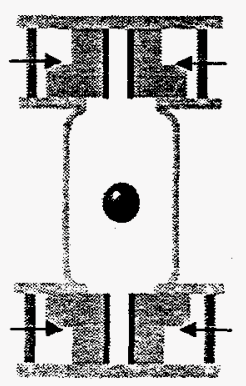

Dynamic hohlraum

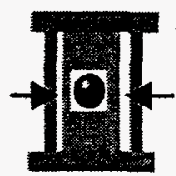

Figure 4. Candidate Target Concepts for $\mathrm{X}-1$. Arrows indicate location and direction of the z-pinch. 


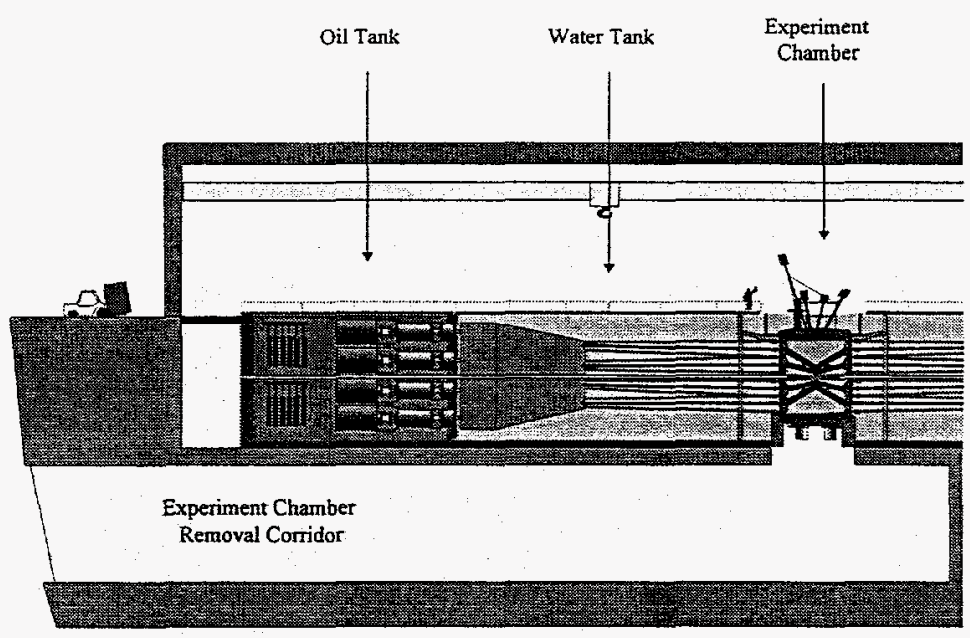

Figure 5. Preconceptual Design of X-1 Pulsed Power Driver and Experiment Chamber using $Z$ technology.

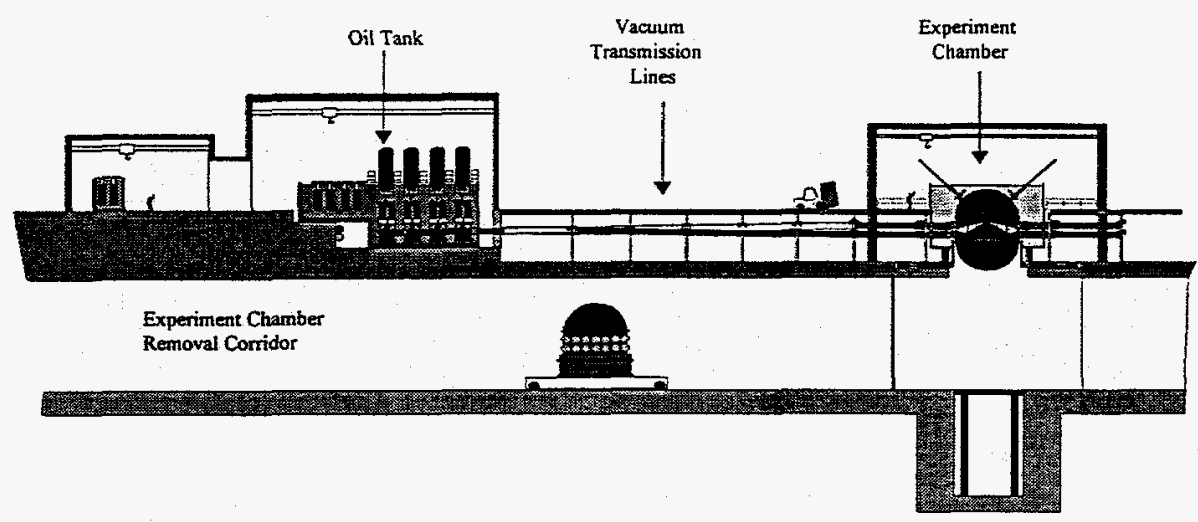

Figure 6. Preconceptual Design of X-1 Pulsed Power Driver and Experiment Chamber using Hermes III technology. 


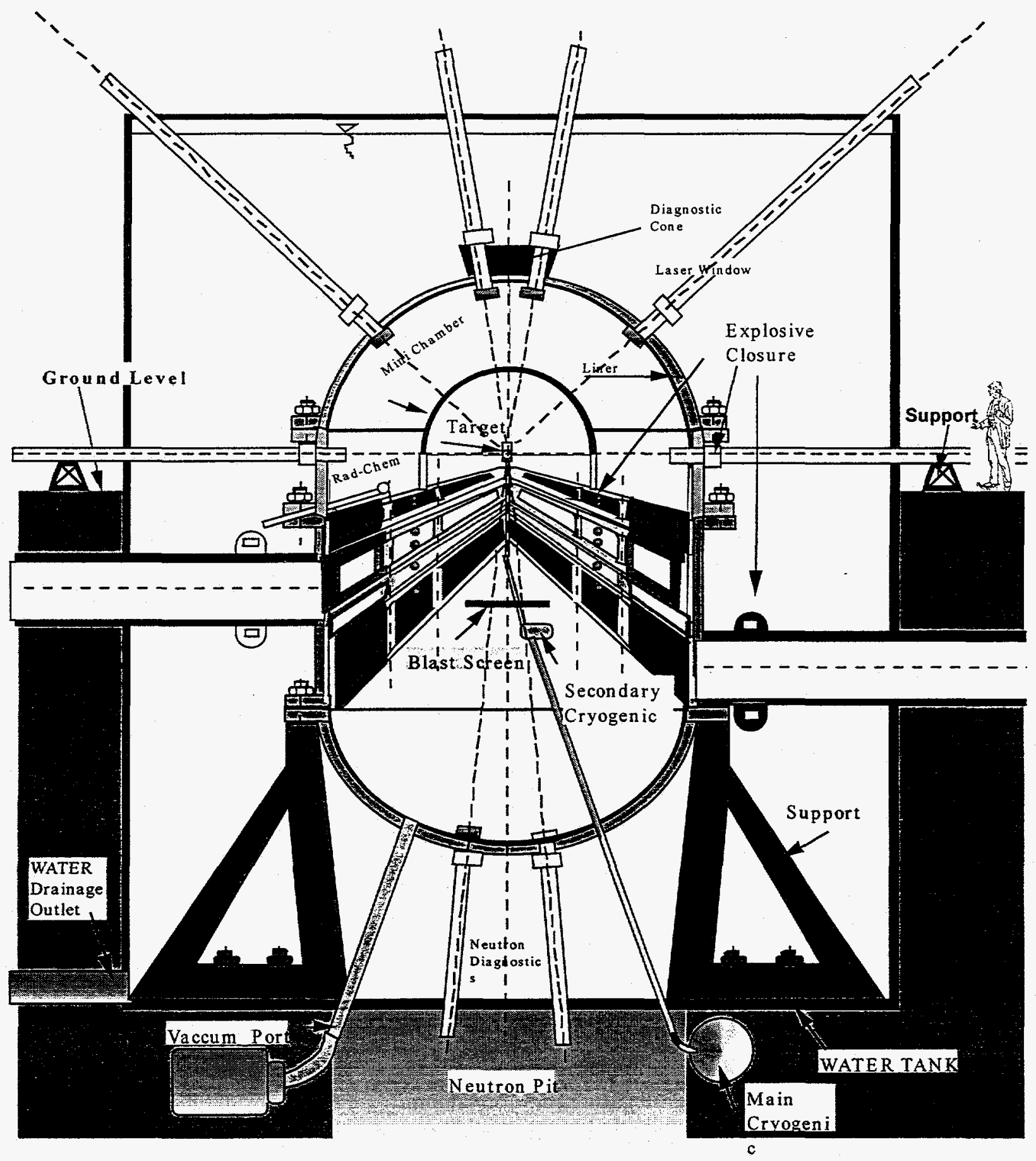

Figure 7. Schematic representation of X-1 Experiment Chamber for containment of radiation and debris. 